\title{
ХИМИЧЕСКАЯ ЗАВИСИМОСТЬ ОТ УПОТРЕБЛЕНИЯ МАРИХУАНЫ: ОТ УДОВОЛЬСТВИЯ ДО БОЛЕЗНИ. СЕРЬЕЗНАЯ ПРОБЛЕМА В ОБЛАСТИ ОБЩЕСТВЕННОГО \\ ЗДРАВООХРАНЕНИЯ В БРАЗИЛИИ
}

\section{ОРИГИНАЛЬНАЯ СТАТЬЯ}

DIAS, Amanda de Araújo1", DIAS, Édina Lúcia de Araújo², OLIVEIRA, Ciane Martins de $^{3}$, DENDASCK, Carla Viana ${ }^{4}$, OLIVEIRA, Euzébio de ${ }^{5}$

DIAS, Amanda de Araújo Dias. Et al. Химическая зависимость от употребления марихуаны: от удовольствия до болезни. Серьезная проблема в области общественного здравоохранения в Бразилии. Revista Científica Multidisciplinar Núcleo do Conhecimento. Год 06, эд. 03, Vol. 11, стр. 7886. Март 2021 года. ISSN: 2448-0959, Ссылка доступа: https://www.nucleodoconhecimento.com.br/здравоохранение/марихуаны, DOI: 10.32749/nucleodoconhecimento.com.br/ru/80478

\section{АБСТРАКТНЫЕ}

Введение: Употребление марихуаны увеличилось во всем мире, будучи наиболее широко используемым незаконным наркотиком в мире. По оценкам, за последнее десятилетие от 167 до 315 миллионов человек в возрасте от 15 до 64 лет использовали некоторые незаконные наркотики. В Бразилии,

\footnotetext{
${ }^{1}$ Медицинский академик в Университетском центре штата Pará - CESUPA.

2 Психолог. Аспирант кафедры психического здоровья в Эскола Верховный да Amazônia - ESAMA.

3 Кандидат медицинских наук. Профессор и исследователь в Университетском центре штата Pará (CESUPA).

${ }^{4}$ Богослов, кандидат медицинских наук в области клинического психоанализа. Он работает в течение 15 лет с научной методологией (метод исследования) в научно-производственном руководстве магистра и докторантуры. Специалист по исследованиям рынка и исследованиям, ориентированным на здоровье.

${ }^{5}$ Кандидат медицинских наук /Тропические болезни. Профессор и исследователь в Федеральном университете Pará - UFPA.
}

RC: 80478

Disponível em: 
приблизительно 7.5 миллиона студентов университета, распределенных в приблизительно 2.400 заведениях используют траву. Метод: Описательное исследование было проведено на основе обзора литературы. Исследование проводилось через базу данных Scielo и виртуальную библиотеку здоровья (BVS). Результаты и обсуждение: Что касается последствий марихуаны, в некоторых исследованиях симптомы, связанные с рекреационным использованием и злоупотреблением этим препаратом, как сообщается. Тем не менее, на академическом уровне, последствия употребления марихуаны могут быть разделены на острые и хронические симптомы. Острые эфрфекты классифицируются как эйфория, фризические эффректы и психические эфреекты, такие как депрессия, галлюцинации, иллюзия, сонливость и нарушения концентрации и кратковременной памяти. Вывод: Некоторые доказательства продемонстрированы, которые могут объяснить, почему люди предпочитают использовать марихуану. Чаще всего острые последствия эйфории, удовольствия и релаксации являются желаемыми, напротив, отмечается, что ущерб, связанный с этим использованием в конечном итоге преодоление иллюзорных преимуществ, которые предлагает препарат, что приводит к удовольствию становится болезнью.

Ключевые слова: марихуана, потребление, удовольствие, болезнь.

\section{1. ВВЕДЕНИЕ}

Привычка к употреблению наркотиков существует и устанавливается в обществах с древности, и первая запись употребления марихуаны (cannabis) восходит по крайней мере десять тысяч лет, в которых Есть записи выращивания и использования различными цивилизациями во всем мире, будучи старейшим в Азии и на Ближнем Востоке, позже прибывающих в Афррику, Америку и другие регионы (ROSA; ROSA, 2018).

$\mathrm{RC}: 80478$

Disponível em: 
По оценкам, за последнее десятилетие от 167 до 315 миллионов человек в возрасте от 15 до 64 лет использовали некоторые незаконные наркотики, что составляет от 3,6 до 6,9\% населения мира. В этом контексте употребление марихуаны возросло во всем мире, что является наиболее широко используемым незаконным наркотиком в мире. Марихуана, по оценкам, потребляется 125 до 203 миллионов человек сегодня, с самой высокой распространенностью в Центральной и Западной Африке (GARCIA, 2014).

В Бразилии около 7,5 миллионов студентов университетов, распределенных примерно в 2400 учебных заведениях, используют траву, и употребление этого вещества является частой практикой, которая широко обсуждается неспециальами и анализируется некоторыми научными исследованиями (GARCIA, 2014; FERNANDES et al., 2017).

В виду того что польза марихуаны все больше и больше часта в нашей социальной окружающей среде, весьма важно что изучения быть сделанным для того чтобы расширить знание о своих химических, психологических и социальных влияниях из-за важности они представляют.

Кроме того, в последние годы идет дискуссия о плюсах и минусах, связанных с легализацией этого препарата, и для профессионалов и населения, чтобы иметь возможность дать свое мнение, необходимо сначала понять, как марихуана изменяет организм в краткосрочной и долгосрочной перспективе (COUTINHO; ARAÚJO; GONTIÈS, 2004).

В этом контексте, эта работа оправдана тем, что создается для того, чтобы уточнить существующие знания об использовании марихуаны и обновить академическое общество о процессе удовольствия и болезни, к которой этот препарат непосредственно связан.

RC: 80478

Disponível em: 
Этот обзор направлен на решение основных аспектов химической зависимости от употребления марихуаны, а также концепции о приятных ощущений от использования этого препарата и как он способствует желанию продолжать его использование. Это также представляет интерес для этой статьи, чтобы обсудить фризические и психологические последствия того, что марихуана берет свое начало в организме, характеризующий процесс болезни его длительного использования, способствуя лучшей информации о причинах не использовать этот препарат.

\section{2. МАТЕРИАЛ И МЕТОД}

Методология, используемая в настоящем исследовании, представляет 1000-е исследование, основанное на обзоре литературы. Библиографические исследования проводились через базу данных Scielo и Виртуальную библиотеку здоровья (BVS). Для поиска рефератов португальцев в таких базах использовались следующие термины: марихуана, удовольствие и болезнь. После этого первоначального процесса, названия были прочитаны, а затем рефераты, чтобы выбрать публикации, которые заинтересованы в исследовании, на основе требований, установленных в качестве критериев включения и исключения. Это исследование было в качестве критериев включения статей, опубликованных в период с 2002 по 2020 год, на португальском языке, в котором рассмотрены темы, связанные с марихуаной и ее основные фризиологические и патологические последствия для человеческого организма, в отношении тела и ума. Критериями исключения являются документы, опубликованные на иностранном языке, которые не отвечают критериям включения. Наконец, отобранные статьи были проанализированы и возникли в написании настоящей работы.

RC: 80478

Disponível em: 


\section{3. ОБЗОР И ОБСУЖДЕНИЕ ЛИТЕРАТУРЫ}

\section{1 ОСНОВНЫЕ ПОНЯТИЯ, КАСАЮЩИЕСЯ МАРИУАНЫ}

Марихуана является трава, чье научное название Cannabis. В Латинской Cannabis означает конопли, которую он называет семьи растений, и Есть три типа видов этого, будучи sativa, indica u ruderalis (FERRARI, 2016). Виды, сатива и индика являются наиболее часто используемыми, как для курения, так и для различных применений в кулинарии и медицине (CORTEZ, 2009).

На протяжении веков население использовало траву марихуаны в лечебных целях, например, китайцы указывали на целебные свойства марихуаны как противосудорожные, успокаивающие и анальгетики. Потенциал его лечебных свойств в лечении некоторых заболеваний уже научно доказан, что требует дальнейших исследований для анализа его воздействия в этой сфере (RIBEIRO; MARQUES, 2008).

Cannabis sativa содержит около 400 химических веществ, по крайней мере 60 алкалоидов, известных как каннабиноиды. Основным психоактивным компонентом растения является тетрагидроканнабиол (ТHC), одно из соединений в траве, которое также состоит из других каннабиноидов, таких как каннабидиол (CBD), каннабинол (CBN) и тетрагидроканнабиварин (THCV). Они делятся на психоактивные (дельта-8-ТГК, дельта-9-ТГК и 11-гидрокси-дельта-9ТГК) и непсихоактивные (каннабидиол и каннабинол). Дельта-9-ТГК известен как самый мощный из каннабиноидов (SOLOWIJ; PESA, 2008; CORTEZ, 2009).

\section{2 ЭФФЕКТ И УДОВОЛЬСТВИЕ}

Основной способ использования травы марихуаны через курение и биодоступность ТНС при курении составляет около 20\%. Другие фрормы использования могут быть выполнены через Нахіхе, который также может быть

RC: 80478

Disponível em:

https://www.nucleodoconhecimento.com.br/здравоохранение/марихуаны 
копченым и имеет более высокие концентрации ТНС, и хеш-масло масло Cannabis, который является жидкой и наиболее мощной фрормой внутривенного препарата. При вдыхании дым, генерируемый обожженной травой, достигает легочного альвеолоса, проникает в кровообращение и достигает мозга в течение нескольких минут (CORTEZ, 2009).

Устные темпы поглощения выше (90 до 95\%) (от 30 до 45 минут) в связи с абсорбцией легких (50\%). Фармакологические эфффекты абсорбции легких может занять от 5 до 10 минут, чтобы начать (SOLOWIJ; PESA, 2008; CORTEZ, 2009).

Пиковые эфффекты, вызванные препаратом, возникают через 30 минут и заканчиваются примерно через два-три часа (CORTEZ, 2009).

Каннабиноиды откладываются в основном в органах, богатых жировой тканью, таких как мозг и яички, и поэтому некоторые пользователи могут проявлять признаки и симптомы интоксикации до 12-24h из-за медленного высвобождения этих веществ адипоцитов (SOLOWIJ; PESA, 2008).

Срок полуиммия ТНС может варьироваться от 20 до 10 до 13 дней, а полная ликвидация может занять до 30 дней. Таким образом, если человек использует марихуану неоднократно с интервалами меньше, чем это, концентрация ТГК в крови будет увеличиваться, вызывая более интенсивные эффекты (SOLOWIJ; PESA, 2008; CORTEZ, 2009).

Сигареты марихуаны, широко найденные, хотя и запрещены в некоторых странах, таких как Бразилия, также известны как "основанные", состоящие примерно из 0,3-1 г марихуаны с концентрацией 1-15\% дельта-9-ТНС (от 2,5 до 150 мг ТНС ). В этом контексте отмечается, что производство эфрфектов эйфории происходит с минимальной концентрацией 1\% THC или 1 сигареты от 2 до 5 мг. И вопреки тому, что многие думают, симптомы интоксикации уже

RC: 80478

Disponível em:

https://www.nucleodoconhecimento.com.br/здравоохранение/марихуаны 
возникают через несколько минут после использования (RIBEIRO; MARQUES, 2008; SOLOWIJ; PESA, 2008).

Что касается последствий марихуаны, в некоторых исследованиях симптомы, связанные с рекреационным использованием и злоупотреблением этим препаратом, как сообщается. Тем не менее, на академическом уровне, последствия употребления марихуаны могут быть разделены на острые и хронические симптомы. Острые эфффекты классифицируются как эйфрория (увеличение сексуального желания, чувство замедления времени, повышенная уверенность в себе и величие, немотивированный смех, веселье, расслабление и повышенное восприятие цветов, звуков, текстур и вкуса), фризические эфрфекты (тахикардия, конъюнктивальная гиперемия, сухость во рту, переохлаждение, головокружение, психомоторная отсталость, двигательное несогласованность, снижение остроты зрения, повышенная острота слуха, бронхолития) , дисреализация, депрессия, галлюцинации, иллюзия, сонливость, нарушения концентрации и кратковременной памяти, панические атаки и паранойя) (SOLOWIJ; PESA, 2008; CORTEZ, 2009).

\section{3 ЗЛОУПОТРЕБЛЕНИЕ И БОЛЕЗНЬ}

Некоторые авторы индуцировать, что потребление психоактивных веществ переживает времена и культуры, используется в религиозных ритуалах, в качестве терапевтического метода и в поисках удовольствия, подчеркивая гедонизм в качестве ссылки в этом процессе (COUTINHO; ARAÚJO; GONTIÈS, 2004).

В краткосрочной перспективе, можно наблюдать вредное воздействие употребления марихуаны, такие как дефицит двигателя, при выполнении таких задач, как вождение, например; и когнитивные проблемы, концентрация и память и, следовательно, трудности в обучении. С другой стороны, длительное применение может быть отмечено хроническим кашлем, измененным

$\mathrm{RC}: 80478$

Disponível em:

https://www.nucleodoconhecimento.com.br/здравоохранение/марихуаны 
иммунитетом, снижением уровня тестостерона и развитием психических заболеваний, таких как шизофрения, депрессия, панические атаки, тревога, раздражительность, демотивация жизнью, галлюцинации и деперсонализации. Чем выше доза потребляется, тем более интенсивными будут последствия и показатели заболеваний. Зависимость от употребления марихуаны происходит в степени ее потребления. К неблагоприятным последствиям относятся амнезия, отсутствие внимания, двигательные проблемы, генерация зависимости и кризисы вывода (RIBEIRO; MARQUES, 2008; SOLOWIJ; PESA, 2008).

Некоторые исследования показывают, когнитивной дисфрункции у потребителей cannabis во время интоксикации, через несколько часов после акта курения, через несколько дней и прочного ущерба в течение более 1 месяца после прекращения использования. Хроника когнитивных изменений зависит от организма, дозы и периодичности, что человек использует траву, но важно подчеркнуть, что с момента первого применения препарата и после начала действия THC, эти психические потери уже проявляются (RIBEIRO; MARQUES, 2008).

Связь между когнитивной работой и частотой употребления cannabis может указывать на остаточный эфффект острой или хронической интоксикации, который, вероятно, рассеивается с прекращением использования. Некоторые исследования сообщают, что восстановление когнитивных функций не полностью выяснено, но в некоторых источниках установлено, что восстановление может произойти после 1 месяца воздержания или не происходит в течение 1 месяца или восстановление может быть только частичным (RIBEIRO; MARQUES, 2008; SOLOWIJ; PESA, 2008).

Использование марихуаны может также привести к структурным изменениям в головном мозге, таких как сокращение объемов гиппокампа и миндалины, и это еще не может быть подтверждено, что эти эффректы обратимы. Но через этот

$\mathrm{RC}: 80478$

Disponível em: 
процесс можно понять реальную причину того, что когнитивные нарушения чаще обнаруживаются в памяти, исполнительной функции, внимания и ингибирования контроля (SOLOWIJ; PESA, 2008).

В этом контексте интересно отметить, что субъект, который использует марихуану может или не может иметь очевидные причины для выполнения такого использования, и среди основных стимулирующих фракторов для потребления наркотиков можно упомянуть: уйти от проблем, любопытство, поиск удовольствий и социального влияния.

\section{4. ВЫВОД}

Можно замезнать, что употребление марихуаны подразумевает ряд как острых, так и хронических последствий, а также остаточных, связанных с механизмом действия ТНС. Кроме того, пользователи этого препарата часто имеют проблемы, которые влияют на их семью, профессиональную и социальную жизнь.

В этом контексте, интересно заметить, что субъект, который использует марихуану может или не может иметь явную причину для выполнения использования, но то, что вызывает желание содействовать исследованиям на мосту между удовольствием и болезнью является то, что стоит за поиск вещества, тот фракт, что находится вне глаз пользователя и сознательного.

В настоящем изучении, некоторые доказательства продемонстрированы которые могут объяснить причины почему индивидуалы выбирают использовать марихуану. Чаще всего острые последствия эйфории, удовольствия и релаксации являются желаемыми, напротив, отмечается, что ущерб, связанный с этим использованием в конечном итоге преодоление иллюзорных преимуществ, которые предлагает препарат, что приводит к удовольствию становится болезнью.

$\mathrm{RC}: 80478$

Disponível em: 


\section{РЕКОМЕНДАЦИИ}

CORTEZ, P. Possíveis efeitos cognitivos e psicomotores em usuários crônicos de Cannabis. 2009.

COUTINHO, M. P. L.; ARAÚJO, L. F.; GONTIÈS, B. Uso da maconha e suas representações sociais: estudo comparativo entre universitários. Psicologia em Estudo, Maringá, v. 9, n. 3, p. 469-477, set./dez. 2004.

FERNANDES, T. F.; MONTEIRO, B. M. M.; SILVA, J. B. M.; OLIVEIRA, K. M.; VIANA, N. A. O.; GAMA, C. A. P.; GUIMARÃES, D. A. Uso de substâncias psicoativas entre universitários brasileiros: perfil epidemiológico, contextos de uso e limitações metodológicas dos estudos. Cad. Saúde Colet., 2017, Rio de Janeiro, 25 (4): 498-507.

FERRARI, C. R. Cannabis. Universidade de São Paulo. Instituto de Física de São Carlos - Psicologia da Educação - SLC 0631. Licenciatura em Ciências Exatas. 2016. $15 p$.

GARCIA, F. D. Manual de abordagem de dependências químicas. ED. Utopika, 2014, 386p.

RIBEIRO, M; MARQUES, A.C. P. R. Projeto diretrizes: Abuso e dependência Maconha. 2008.

ROSA, P.; ROSA, M. G. Políticas sobre cannabis: um estudo comparativo sobre os modelos da Espanha. Geographia Opportuno Tempore Universidade Estadual de Londrina EISSN: 2358-1972, Volume 4, Número 1, 2018 Uruguai e Colorado/EUA, 2018.

SOLOWIJ, N,; PESA, N. Anormalidades cognitivas no uso da cannabis. 2010.

RC: 80478

Disponível em: 
Представлено: Март 2021.

Утверждено: Март 2021 года.

RC: 80478

Disponível em:

https://www.nucleodoconhecimento.com.br/здравоохранение/марихуаны 